\title{
Using Indices to Capture Vulnerability for Development Finance in SIDS
}

Knowledge for Development Programme

19 April 2021

\section{Question}

How can we best assess when the economic, social and environmental resilience of SIDS are compatible with the sustainable reduction of external support?

\section{Contents}
1. Summary
2. Background
3. External Support for SIDS Based on Vulnerability Indices
4. Other Economic, Social, and Environmental Indices
5. Attempts to Reconsider Allocation Approaches
6. Alternatives, Criticisms, and Other Considerations
7. Conclusion
8. References

The K4D helpdesk service provides brief summaries of current research, evidence, and lessons learned. Helpdesk reports are not rigorous or systematic reviews; they are intended to provide an introduction to the most important evidence related to a research question. They draw on a rapid deskbased review of published literature and consultation with subject specialists. other Government departments, but the views and opinions expressed do not necessarily reflect those of FCDO, the UK Government, K4D or any other contributing organisation. For further information, please contact helpdesk@k4d.info. 


\section{Summary}

A key issue when it comes to aid allocation to Small Island Developing States (SIDS) is whether current measures of development - such as income per capita - are truly able to reflect the unique set of challenges that these countries face. Inability to accurately measure development in SIDS can lead to substantial risk. On the one hand, aid allocation that solely relies on income levels may result in an unsustainable reduction in external support to SIDS, leaving them to face high levels of economic, environmental, and social vulnerability. On the other hand, an inadequate measure of vulnerability can lead to no clear pathway to the reduction in aid, making it very improbable for SIDS to become self-reliant, no matter how far they develop or climb the income ladder

This aim of this paper is twofold. The first is to look at whether vulnerability indices can help determine the levels of external support SIDS need. The second is to consider how this can help in determining when support can be reduced or terminated. This is achieved by considering the different indices that international organisations and multilateral development banks use to capture the vulnerability of SIDS, how they use these indices to determine thresholds for aid allocation, and the advantages and disadvantages of applying each.

A few international organisations use indices and other measures to determine aid allocation for SIDS. The UN uses a vulnerability index (UN EVI) to determine Least Developed Country (LDC) status and, consequently, access to aid for SIDS, but overcoming vulnerability is not a necessary condition for graduating from LDC. The World Bank gives SIDS access to concessional International Development Association (IDA) resources even if their per capita income exceeds IDA's operational cut-off. However, it does not use an 'official' measure for SIDS vulnerability. The Caribbean Development Bank is the only one that formally uses a vulnerability index along with GNI per capita to account for the needs of SIDS.

There have been some attempts by other multilateral development banks to use a vulnerability index in their allocation criteria. The World Bank considered an approach that would link IDA's allocations to a country's vulnerability but found it to be inappropriate due to various structural and distributive reasons. Similarly, the Africa Development Bank (AfDB) trialled the inclusion of a vulnerability index but found it costly and risky, especially in terms of data collection. The Asia Development Bank (AsDB) recently approved the inclusion of a vulnerability index to its new allocation formula (starting in 2021) that will give eligible SIDS a premium based on their vulnerability classification.

There is also very little in the literature that discusses when vulnerability is at a threshold that makes the reduction in external support for SIDS sustainable. One of the main reasons for this is that vulnerability as it is defined by most organisations is meant to capture the inherent characteristics of SIDS, which are time invariant and arguably cannot be diminished or improved over time through aid.

The exception to this is the Vulnerability and Resilience Framework, developed by the Commonwealth Secretariat; it advocates that, for the allocation of external support to SIDS, the measure of inherent vulnerability should be offset by a measure of resilience, which capture the policies in response to said vulnerability. This framework implies that small vulnerable states are not destined to eternally remain vulnerable to external shocks but can adopt policy measures to enable them to improve their ability to cope and bounce back. In that case, although SIDS tend 
to be highly vulnerable, this condition is not considered to be an entitlement for aid nor an exception from it.

Including vulnerability as a dimension for consideration when discussing SIDS external support allocation is not without its criticism. Some argue that any economic-centric approach to aid in SIDS is misguided, as its main challenges are environmental, pertaining to climate change and the degradation of biodiversity. Experts contacted for this rapid review generally agree that a reduction in external support to SIDS is not likely to be sustainable, especially for smaller islands and especially as the effects of climate change worsen over time and start taking more of a toll on the lives of island people.

\section{Background}

\section{Characteristics of SIDS}

The SIDS classification started to gain traction in 1992, when it was used to identify and draw attention to shared characteristics and challenges between these countries. These shared characteristics stem from SIDS's small population size and remoteness, as well as exposure to the worst consequences of climate change (UN, 2020).

Most SIDS have small, dispersed population sizes and territories that are remotely located from economic markets (Alonso et al., 2014). This has several direct implications such as high cost of transport, limited human resources, and challenging service delivery (Herbert, 2019). They also have an impact on economic structure, as they result in economies of scales and economic diversification to be particularly difficult (UN, 2020). This means that the economy is particularly vulnerable to external shock, as they rely on few sectors (e.g., tourism, services, agriculture and fishing). This is exemplified by consequences of the collapse of tourism at the onset of the COVID-19 pandemic; SIDS were one of the worst hit developing economies, as their GDP dropped by $6.9 \%$ in 2020 (OECD, 2021). Economic vulnerability to external shocks is compounded due to a large informal sector, narrow tax base, and an open economy (Herbert, 2019; UN, 2020).

Climate change vulnerability is also a shared characteristic across SIDS. This includes threats resulting from extreme weather, biodiversity loss, and ocean acidification (UN, 2020). SIDS are also exposed to rises in sea-levels and storms (OECD, 2018b) and are expected to face significant changes in average temperature and rainfall (Herbert, 2019; UN, 2015). Besides the existential threat, climate change also has an economic effect, as it limits opportunities for economic investment. However, while SIDS are located in some of the world's most disasterprone regions, some argue that natural hazards do not always cause disasters unless they are combined with a lack of capacity to manage or adapt (OECD, 2018b; UN, 2020).

These aforementioned characteristics result in both a higher reliance on overseas development aid and a constrained ability to absorb it (UN, 2020). This is due to limited institutional capacity and challenges to the implementation of development projects without external technical and financial support. Additionally, studies on small remote state are disproportionally expensive to run, resulting in insufficient data and analysis on SIDS in general (UN, 2020) 
Despite these shared characteristics, SIDS remain a very diverse set of countries. They vary in location (Caribbean Ocean, Pacific Ocean, African Indian Ocean, and South China Sea), income group (ranging from high income like the Bahamas, to lower income like Guinea-Bissau), loan eligibility, human development indicators, and population density, and as a result, experience very context specific set of challenges outside the ones they have in common. Perhaps due to this heterogeneity, there is no specific criteria of eligibility to belong to SIDS, as membership is largely based on self-appointment (Alonso et al., 2014).

\section{Income as a Measure for Development}

A central issue to this rapid review and to the external support of SIDS is the suitability of current measures of development to capture their specific characteristics. Specifically, some argue that income per capita may not be appropriate as it does not reflect the unique set of challenges that these countries face (Briguglio et al., 2009; Guillaumont, 2010). Indeed, the use for income generally Gross National Income (GNI) per capita - as a measure for aid is not only controversial when it comes to SIDS but more generally for all developing countries (Herbert, 2019).

Income indicators generally measure one single characteristic of a country, whereas development is widely acknowledged to be a much broader and much more complex process that cannot be captured by a single variable. However, one of the reasons that it persisted is because it is easily available and easy to standardize. As a result, it makes it straightforward to benchmark the experience of one country against other and, consequently, determine its need for external support, or lack thereof (Herbert, 2019).

To account for these weaknesses, some financing bodies and doner organisations complement the GNI per capita measure with other indices to determine a country's needs. For example, as will be discussed Section 3, the UN uses two indices along with GNI per capita to determine which countries can be deemed part of the Least Developed Countries (LDC) group and receive financial assistance as a result (Ancharaz, 2019).

One of the measures that is especially relevant for the case of SIDS is vulnerability. As explained, SIDS are likely to be particularly exposed to external shocks due to their inherent geographic, economic, and climate characteristics. The definition of vulnerability and the way it is captured varies, but it is generally agreed that it should only measure factors that make a certain country intrinsically susceptible to shocks, independent of the country's present policies and measures (Wang, 2013; Baldacchino, 2015; Feindouno \& Guillaumont, 2019).

The special characteristics of SIDS are starting to gain recognition from international bodies (Asia Development Bank, 2019a; OECD, 2018b; UN, 2020; World Bank, 2018b). As a result, some introduced exceptions on concessional finance that encompass SIDS (e.g. the World Bank's Small Island Economies Exception), while others have considered and attempted the inclusion of a vulnerability measures in their calculation to allocate more concessionary funds to SIDS (Africa Development Bank, 2019b; Asia Development Bank, 2019a). However, only one financing body, the Caribbean Development Bank, formally uses a vulnerability index for allocating concessionary finances and to account for the special characteristics of SIDS (Caribbean Development Bank, 2017). The details of all these attempts and measures will be discussed in Section 3. 


\section{External Supports to SIDS}

According to OECD (2018b), concessional finance provided by the international community to SIDS accounted for $27 \%$ of external flows to these countries between 2012 and 2015, but represents only $2.1 \%$ of the GNI of SIDS. However, there is big variation within this average, with some extreme cases like Tuvalu, where concessional finance accounts for $90 \%$ of GNI. Although SIDS receive a fraction of the total volume of concessional finances to developing countries, it remains relatively high given the size of the population, at USD 96 per capita. The cost of delivering aid given the diseconomies of scale is particularly high for SIDS (OECD, 2018b).

The bulk of concessional aid to SIDS comes from bilateral providers (79\%) as a result of proximity, geopolitical ties, and strategic and economic interests. They are often a one-off transfer in response to emergencies. Multilateral donors are increasingly playing a role in financing SIDS, with the largest bulk coming from the International Development Association (IDA). SIDS are also a site of South-South cooperation, as 'non-traditional' donors, including China, Russia, Indonesia, and the United Arab Emirates, are emerging as a source of financing options for small islands (OECD, 2018b).

Caribbean SIDS are the largest receivers of external support flows among SIDS, mainly due to the large allocation that goes to Haiti and the Dominican Republic. However, Pacific SIDS receive the highest per capita allocation. Around $64 \%$ of external flows goes to six SIDS; besides the aforementioned two, these include Papua New Guinea, Timor-Leste, Cabo Verde, Solomon Islands, and Cuba (OECD, 2018b).

The case for providing external support to SIDS is strong. Besides their aforementioned unique economic, environmental, and social need, Guillaumont and Guillaumont-Jeanneney (2009) argues that aid to SIDS is marginally more effective because of their vulnerability. This is because aid that goes to vulnerable countries has a stabilising effect. This argument is one reason to justify why international organisation should include - or at least attempt to include - an index of economic vulnerability in their allocation formula. These will be discussed in Section 3.

\section{External Support for SIDS Based on Vulnerability Indices}

\section{The United Nations Economic and Environmental Vulnerability Index (UN EVI)}

The UN EVI is used to measure Least Developed Country (LDC) status. The LDC category was established to distinguish low-income countries that face structural barriers to sustainable growth (Ancharaz, 2019). This used to be measured by income per capita, literacy rate, and the share of manufacturing in GDP. However, this was replaced in 1991 by two indices, one referring to human status and the other to economic diversification. This was revised again in 1999; LDC is now identified through GDP per capita, an index of human capital (HAI - which will be discussed in Section 4), and the then-new UN EVI. The components of the UN EVI is revised every three years by the Committee for Development Policy (CDP) (Guillaumont, 2010).

The current UN EVI is a composite index calculated from eight component indices, made up of four economic vulnerability measures (share of agriculture, forestry, and fisheries in GDP; remoteness and landlocked-ness; merchandise export concentration; and instability of exports of 
goods and services) and four environmental measures (share of population in low elevated coastal zones; share of population living in drylands; instability of agricultural production; and victims of disaster). The index is constructed by giving equal weights to each of the aforementioned 8 measures different factors (UN, 2021a). Figure 1 illustrates these components.

See: Figure 1: Components and weights of UN EVI, Source: UN (2021a), https://www.un.org/development/desa/dpad/least-developed-country-category/ldc-criteria.html

To be considered an LDC, a country needs a UN EVI of 36 . To be eligible for graduation from LDC status, the threshold that the LDC needs to meet is set at $10 \%$ below the inclusion threshold at 32 (UN, 2010). While a low EVI is a required criterion for inclusion in LDCs, it is not necessary for graduation; a country can graduate from the LDC status by achieving either two of the three criteria (reaching the threshold of EVI, HAI, or GNI per capita), or if its GNI per capita is at least twice the graduation threshold (the 'income only' graduation rule) (Ancharaz, 2019). Therefore, as it stands, reduction in aid through graduating from LDC can happen while a country is still vulnerable.

Indeed, all the SIDS classified as LDCs that are expected to graduate are projected to do so without meeting the UN EVI threshold; Vanuatu, Tuvalu, Kiribati, São Tomé and Príncipe, and the Solomon Island are projected to meet the graduation criteria in 2024 by surpassing the threshold only in income and HAI. Timor-Leste is expected to graduate by meeting the 'income only' rule (Ancharaz, 2019). This is consistent with previous patterns as all SIDS that have previously left the LDC list, except for the Maldives, did so without passing the UN EVI threshold, including Samoa and Cabo Verde (Ancharaz, 2019).

This means that SIDS tend to graduate with high levels of economic and environmental vulnerability. Because of this, some countries requested that an LDC should not be made to exit the list until it is no longer vulnerable, implying that UN EVI would become a 'compulsory' graduating criterion (Guillaumont, 2010). SIDS, therefore, ask to continue to receive LDC level of financial assistance, until they surpass the vulnerability threshold. However, as Guillaumont (2010) argues, if this happens then the asymmetry between the inclusion and exit criteria becomes even deeper. In other words, inclusion will require bad performance in three benchmarks, while graduating will only take place if all three criteria is met. This would create an inequitable treatment for other developing countries and an uneven distribution of foreign assistance. It will also make graduation very improbable for SIDS, even those rated as upper middle-income countries.

Looking at examples of SID LDC graduation shows mixed findings. International organisations like the UN and the OECD hail Cabo Verde and Samoa as success stories (OECD, 2018a; UN, 2018). Both countries show healthy improvement in HAl indicators, but their UN EVI remain much higher than average, above the LDC threshold (Quak, 2019). Since graduating, both countries have also moved from "moderate" debt risks to "high" debt risk by the IMF (Quak, 2019). According to the final monitoring report on LDC graduation for Samoa, the UN states that the country has continued to make progress since graduation in 2014 and to meet the challenges that it is facing. This was attributed to the stability and the political leadership as well as to the 
well-educated and relatively healthy population (UN, 2018). In general, as Quak (2019) concludes, there are too many factors at play to conclusively assess whether SID LDC graduation is sustainable. This is especially true given the ongoing COVID-19 pandemic. Samoa is facing unprecedented challenges due to major hits on its main income sources, including tourism and remittances. As this is a recent development, it is unclear what this means for the country's vulnerability and transition (UN, 2021b).

Therefore, the vulnerability of these countries remains an issue of concern. This is not just relevant for SIDS graduating from LDC, but for all SIDS that are climbing up the income level ladder and, as a result, receiving less aid. Since most SIDS are middle-income countries, they are not eligible for most type of aid and concessional resources from multilateral institutions, despite potentially needing it (Quak, 2019). Therefore, Guillaumont (2010) proposes that economic vulnerability measured by the UN EVI should be a parameter to be considered for all aid policies. Despite the general agreement with this among the international donor communities, per capita income remains the most popular measure by which concessional finance and aid are determined (Briguglio, 2018, p. 87).

\section{World Bank's Small Island Economy Exception (SIEE)}

In 1985, the World Bank approved the SIEE, which allows small island economies to access concessional IDA resources even if their per capita income exceeds IDA's operational cut-off (World Bank, 2018b). This was an acknowledgement of small islands' special characteristics which result in similar challenges to those faced by low-income countries, namely: vulnerability to external economic shocks, high per-capita costs of infrastructure and industry investments, weak institutional capacity, limited skills, and lack of creditworthiness. In 1985, six small island economies due to graduate from IDA were granted the Exception. Back then, it was envisioned that the Exception will apply to other small island economies on a case-by-case basis (World Bank, 2018b).

In addition to vulnerability to economic shocks, more recent assessments have also considered vulnerability to natural disasters and climate change as part of the rationale for granting the exception. For example, this was the rational for granting the Marshall Islands, the Federal States of Micronesia, and Tuvalu the Exception in 2011 (World Bank, 2018b). Currently several middle-income small island states have access to IDA under the Exception, including 10 countries with IDA-only status and seven Blend countries (IDA and IBRD eligibility) (World Bank, 2020). The majority of beneficiary countries are Microstates, with a population of less than 200,000, primarily in the Pacific and the Caribbean Oceans (World Bank, 2018b).

Countries under the SIEE receive IDA credits on the most concessional lending terms that IDA offers - the Small Economy Terms, at no interest, 40-year amortisation, with a 10-year grace period. Once granted SIEE, a country continues to enjoy its benefits - regardless of the country's per capita income; SIEE countries are eligible for IDA concessional credits on Small Economy Terms until they graduate to International Bank for Reconstruction and Development (IBRD)-only status. Except for St. Kitts and Nevis (which was granted the Exception in 1985 and graduated to IBRD only status in 1994), all island economies that were granted the Exception have remained IDA eligible (World Bank, 2018b).

The SIEE was reviewed as part of the IDA18 Mid-term Review(World Bank, 2018a). The three main issues identified in implementing the SIEE Policy were the need for clear entry/re-entry 
criteria for considering requests from IBRD-only countries; the need for exit criteria for countries already under SIEE; and the need to explicitly recognise vulnerability to natural disasters and climate change as part of the rationale for granting SIEE. The review proposes that an IBRD-only SIEE may enter/re-enter IDA if the following four conditions are satisfied: the country's per capita income is at or below the Graduation Income; the country has limited access to IBRD resources; the country has limited creditworthiness for accessing commercial credit and the country is assessed as highly vulnerable to natural disasters and climate change (World Bank, 2018a).

The SIEE Policy does not contain an exit provision. This has resulted in several countries continuing to be eligible for IDA Small Economy Terms despite having per capita incomes well above the IDA operational cut-off, ranging from USD6,990 to USD9,650. For some, the per capita incomes exceed the level that typically initiates discussions on graduating from the IBRD (World Bank, 2018a). According to World Bank, the IDA's overall philosophy is to support the poorest and the most vulnerable countries. Therefore, it is important to assess whether the existing SIEE Policy Framework provides adequate incentives for high-income small states to graduate from IDA. A higher level of development and resilience to shocks could trigger IDA Blend terms. Such an approach would recognise that the ability of a Small State to cope with shocks increases with development, while also recognising that even at higher levels of development, some Small States may be more vulnerable compared to other economies. It would help smooth the transition in the terms of financing for this group of countries ${ }^{1}$ (World Bank, 2018a).

\section{Caribbean Development Bank Multidimensional Vulnerability Index (CDB VI)}

The Caribbean Development Bank (CDB) allocates a Special Development Fund (SDF) based on factors that are meant to reflect a country's need and a country's performance. The former includes population, per capita income, and vulnerability. Vulnerability is estimated using a Vulnerability Index (henceforth the CDB VI). Because the vulnerability index is one of several criteria that is used to determine whether a country received funds and the size of the allocation, the CDB regularly revises and updates the CDB VI (Caribbean Development Bank, 2017; Ram et al., 2019).

According to Ram et al. (2019), the design of the original CDB VI was informed by the work of Briguglio $(1992,1995)$ and was initially estimated by Crowards $(2000)$. It relies mainly on economic indicators, the following 6 sub-indices:

- Peripherality and accessibility provides an indication of remoteness from major economic trading partners measured by freight and insurance costs for imports.

- Dependence upon imported energy measured by imports net of exports of energy.

- Export concentration measured as the percentage of total export receipts and accounted for by the major export and the top three exports. This includes both export of goods and services and is combined with information on the openness of the economy measures as total export earnings as a percentage of GDP.

The details of this transition were to be explored in the IDA19 negotiations. However, available IDA19 documents make no mention of this. 
- Convergence of export destination, measured in terms of the percentage of total export receipts, accounted for by the single most-important destination and the top three mostimportant destinations. This includes the exports of goods and services and is combined with information on the openness of the economy, that is measured as total export earnings as a percentage of GDP.

- Reliance upon external finance, measured by a combination of two variables, i.e., overseas development assistance as a proportion of annual gross fixed capital formation and foreign direct investment as a proportion of annual gross fixed capital formation.

- Susceptibility to natural disasters, measured as the cumulative number of persons affected and deaths caused by natural disasters between 1950 and 1998, each as a proportion of the total population.

In 2019, CBD updated and revised the CDB VI to widen its coverage and include social vulnerability and a climate change component (Ram et al., 2019). The latter not only considers previous natural hazard events, but also predicts how the environment is likely to cope with future events. Social vulnerability, and susceptibility to natural hazards are not causes of vulnerability but were determined to be an important factor of the CDB VI because they can aggravate the negative impact of economic shocks (Ram et al., 2019).

The social vulnerability indicator includes five measures (Ram et al., 2019):

- Education (proportion of population with tertiary education, adult literacy rate).

- Health (life expectancy at birth).

- Security, social order and governance (murders per 100,000 population).

- Resource allocation (proportion of children and working age persons belonging to the poorest quintiles).

- Communications architecture (computer literacy rate).

The climate change component includes factors contributing to environmental vulnerability, encompassing six indicators (Ram et al., 2019):

- Natural disasters: increased intensity and frequency.

- Climate change: sea level rise, coastal erosion.

- Oceans and seas: exploitation of marine resources.

- Biodiversity: deforestation and desertification and invasion of alien species.

- Water: over exploitation of surface ground and coastal water and saline intrusion, and

- Waste: insufficient waste treatment.

Additional changes include renaming the Peripherality and Energy Sub-Index the Strategic Imports Sub-Index (SISI), removing the proxy indicator freight and insurance, adding a new food proxy indicator (food imports as a percentage of total merchandise imports). Official Development Assistance (ODA) proxy indicator was replaced with remittances (Ram et al., 2019).

The updated and revised CDB VI, therefore, comprises three dimensions of vulnerability (economic, social, and environmental) and six sub-indices (export concentration; concentration of export destination; dependence on strategic imports; reliance upon external finance; social vulnerability, and susceptibility to natural hazards and climate change). The components of the composite index is shown in Figure 2; the index is calculated by taking the arithmetic average of the sub-indices (Ram et al., 2019). 


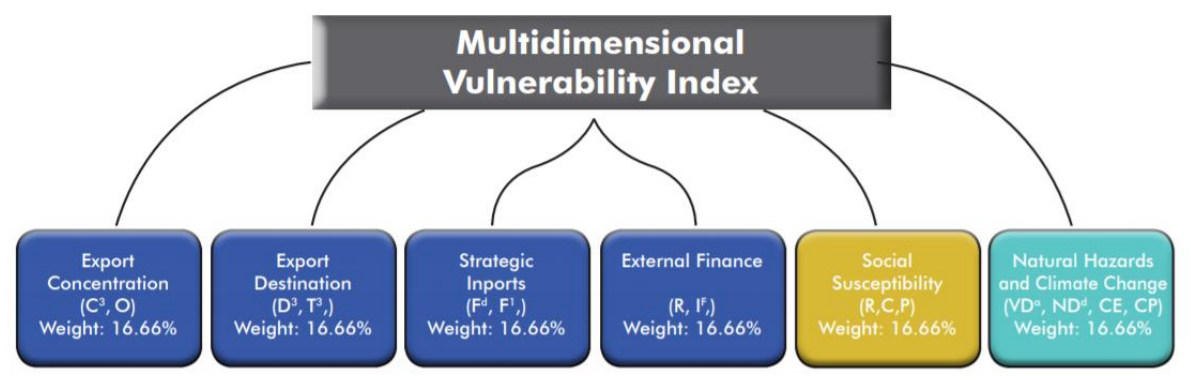

Source: Ram et al (2019, p. 22), reproduced with permission.

In Ram et al. (2019), the CDB index is calculated for its Borrowing Member Countries (BMCs) to gain deeper understanding of the relative vulnerabilities of SIDS. The main findings indicate that the BMCs, on average, are middle-to-high vulnerability countries with an average vulnerability index score of 0.54 for 2017. The vulnerabilities are a result of the dependence on few major export products and trading partners, high levels of energy imports, social challenges, and exposure to natural hazards and climate change. Although resource-rich countries had lower vulnerability scores, the paper notes that these economies have unique challenges related to sharp boom and bust cycles and higher levels of inequality, among others.

Most BMCs are within the medium-high classification of vulnerability to external shocks as shown in Table 1. These thresholds were adjusted to align the with that of the Commonwealth Secretariat (discussed in the next section), with 0 to 0.33 indicating low vulnerability; 0.34 to 0.49 indicating medium-low vulnerability; 0.50 to 0.69 indicating medium-high vulnerability; and 0.70 to 1.00 indicating high vulnerability. Table 1 illustrates the CBI VI scores for various SIDS using the aforementioned categories. 


\begin{tabular}{|c|c|c|c|c|c|c|c|c|c|c|c|c|}
\hline & \multicolumn{4}{|c|}{ Economic } & \multicolumn{4}{|c|}{ Social } & \multicolumn{4}{|c|}{ Environmental } \\
\hline & \multicolumn{2}{|c|}{2016} & \multicolumn{2}{|c|}{2017} & \multicolumn{2}{|c|}{2016} & \multicolumn{2}{|c|}{2017} & \multicolumn{2}{|c|}{2016} & \multicolumn{2}{|c|}{2017} \\
\hline & Score & Rank & Score & Rank & Score & Rank & Score & Rank & Score & Rank & Score & Rank \\
\hline Anguilla & 0.55 & 9 & 0.58 & 9 & 0.42 & 16 & 0.39 & 16 & & & 0.55 & 4 \\
\hline $\begin{array}{l}\text { Antigua and } \\
\text { Barbuda }\end{array}$ & 0.52 & 12 & 0.55 & 10 & 0.50 & 13 & 0.60 & 11 & 0.41 & 7 & 0.42 & 6 \\
\hline Bahamas, The & 0.57 & 7 & 0.65 & 5 & 0.51 & 12 & 0.52 & 13 & 0.32 & 11 & 0.30 & 13 \\
\hline Barbados & 0.58 & 6 & 0.58 & 8 & 0.43 & 15 & 0.45 & 15 & 0.11 & 14 & 0.10 & 17 \\
\hline Belize & 0.63 & 3 & 0.65 & 4 & 0.71 & 3 & 0.71 & 2 & 0.32 & 10 & 0.30 & 14 \\
\hline Cayman Islands & 0.61 & 5 & 0.60 & 7 & 0.05 & 17 & 0.07 & 17 & 0.45 & 5 & 0.40 & 7 \\
\hline Dominica & 0.45 & 15 & 0.48 & 14 & 0.54 & 11 & 0.62 & 8 & 0.56 & 3 & 0.66 & 1 \\
\hline Grenada & 0.51 & 13 & 0.60 & 6 & 0.69 & 5 & 0.69 & 3 & 0.41 & 6 & 0.39 & 8 \\
\hline Guyana & 0.56 & 8 & 0.55 & 11 & 0.64 & 6 & 0.61 & 10 & 0.59 & 2 & 0.56 & 3 \\
\hline Haiti & 0.73 & 1 & 0.77 & 1 & 0.64 & 7 & 0.64 & 6 & 0.60 & 1 & 0.59 & 2 \\
\hline Jamaica & 0.67 & 2 & 0.69 & 2 & 0.70 & 4 & 0.68 & 4 & 0.22 & 13 & 0.20 & 16 \\
\hline Montserrat & 0.42 & 16 & 0.41 & 16 & 0.62 & 8 & 0.62 & 7 & 0.26 & 12 & 0.24 & 15 \\
\hline Saint Kitts and Nevis & 0.49 & 14 & 0.53 & 12 & 0.61 & 9 & 0.61 & 9 & & 15 & 0.42 & 5 \\
\hline Saint Lucia & 0.63 & 4 & 0.69 & 3 & 0.79 & 1 & 0.68 & 5 & 0.46 & 4 & 0.34 & 11 \\
\hline $\begin{array}{l}\text { Saint Vincent and the } \\
\text { Grenadines }\end{array}$ & 0.53 & 11 & 0.50 & 13 & 0.73 & 2 & 0.78 & 1 & 0.41 & 8 & 0.33 & 12 \\
\hline Suriname & 0.39 & 17 & 0.47 & 15 & 0.60 & 10 & 0.56 & 12 & 0.39 & 9 & 0.35 & 10 \\
\hline Trinidad and Tobago & 0.34 & 18 & 0.38 & 17 & 0.46 & 14 & 0.51 & 14 & 0.00 & 15 & 0.00 & 18 \\
\hline AVERAGE & 0.54 & & 0.57 & & 0.57 & & 0.57 & & 0.32 & & 0.36 & \\
\hline
\end{tabular}

Source: author's calculations.

\section{The Commonwealth's Vulnerability-Resilience Framework}

There is disagreement with regards to the quality of a UN EVI as a measure for vulnerability. For one, the variables used to construct the index are subjectively selected. More importantly, the indicator does not distinguish between intrinsic characteristics and characteristics related to policy. Wang (2013), for example, argues that trade share, export concentration and the share of agriculture, forestry and fisheries in GDP all reflect properties of developing economies, but are subject to change through economic policies. The UN EVI therefore measures both the exogenous shocks to the economy and the characteristics of the policies in place that may lessen or exacerbate the negative impacts of the shocks.

The vulnerability-resilience framework was developed by experts commissioned by the Commonwealth Secretariat to distinguish between economic resilience - which is developed and managed as a result of deliberate policy - and economic vulnerability, which is due to inherent features of the economy. This framework implies that small vulnerable states are not destined to eternally remain vulnerable to external shocks but can adopt policy measures to enable them to improve their ability to cope and bounce back (Briguglio et al., 2009). The rest of this section will discuss how the vulnerability and resilience framework is developed as described by Baldacchino (2015).

The vulnerability part of the framework measures permanent or semi-permanent characteristics that a country can exercise no control over and is unrelated to policy approaches, misguided or otherwise. Countries scoring highly on the vulnerability index are, therefore, not responsible for their vulnerability. The resilience index, on the other hand, would refer to what a country can do 
about its vulnerability; in other words, if the policies that are in place will lessen or worsen its intrinsic vulnerability. Therefore, this index will measure the appropriateness of policy measures that are put in place. When the vulnerability and resilience index are combined, the results would elucidate the overall risk of being affected by external shocks due to inherent vulnerability feature, which is offset to different extents by policy measures.

The economic vulnerability index (EVI) proposed in Baldacchino (2015) is comprised of four components: (i) trade openness; (ii) export concentration; (iii) dependence on strategic imports, and (iv) proneness to natural disasters. While the trade openness component is arguable a policy measure, it is included in the economic vulnerability index because it is a permanent feature of small states as a result of to their small domestic market. Trade openness can be a source of exposure to external shocks over which a country has no or very limited control over, especially when it depends on a few export items and strategic imports. Finally, proneness to natural disaster is included because such disasters are likely to aggravate the effects of external economic shocks and may themselves lead to economic shocks.

The economic resilience index (ERI) proposed in Baldacchino (2015) has five components; (a) macroeconomic stability (b) market flexibility (adjusted for financial riskiness); (c) political governance and institutions; (d) social development, and (e) environmental management. Social development is a non-income component relate to education (measured by mean years of schooling and expected years of schooling) and health (measured by life expectancy).

As for environmental governance, it makes use of the environmental performance index (EPI), which attempts to quantify the environmental performance of a country's policies. It uses the weighted average of 10 policy categories which are: (a) environmental burden of disease; (b) water (effects on human health); (c) air pollution (effects on human health); (d) air pollution (ecosystem effects); (e) water resources (ecosystem effects); (f) biodiversity and habitat; (g) forests; (h) fisheries; (i) agriculture, and (j) climate change. These policy categories were grouped into two broad policy objectives, namely (i) environmental health (EH) which includes the first three categories and measures the environmental impact on human health, and (ii) ecosystem vitality (EV), which measures ecosystem health and natural resource management, covering the remaining seven policy categories.

Combining the EVI and ERI on the $y$ - and $x$-axis respectively results in four quadrants, each showing a different combination of levels of vulnerability and resilience. Risk in this context can be calculated as the difference between vulnerability and resilience. Countries can be grouped into one of the four categories based on their values of EVI and ERI - high vulnerability and low resilience, low vulnerability and high resilience, low vulnerability and low resilience, and high vulnerability and high resilience.

The thresholds are calculated to be the average for all countries. Most SIDS are classified in the two high vulnerability quartiles. Some are also low resilience (Comoros, Guinea Bissau, Haiti, São Tomé/Príncipe, and the Solomon Islands) and some are high resilience (Antigua/Barbuda, Bahamas, Barbados, Belize, Dominica, Fiji, Mauritius, St Lucia, Samoa, Singapore, Tonga, Trinidad/Tobago, and Vanuatu). The highest concentration of SIDS, however, belong to the borderline case of high vulnerability and medium resilience, constituting 11 out of the 15 countries in this category (Cabo Verde, Grenada, Guyana, Jamaica, Kiribati, Maldives, Marshall Islands, Papua New Guinea, St Kitts \& Nevis, St Vincent/Grenadines, and Seychelles). 
Therefore, although small states tend to be highly vulnerable, this condition is generally not considered to be an entitlement for aid, nor an exception from it.

This framework was developed by experts commissioned by the Commonwealth Secretariat and it provides a better understanding of where to target aid and how to combat vulnerability. The index has been used to profile three SIDS (St Lucia, Seychelles, and Vanuatu) in order to benchmark their experience against global measures of EVI and ERI and to inform domestic policy (Baldacchino, 2015). Although it was not used in the context of aid allocation, this approach provides an aggregate score upon which aid can theoretically be apportioned. The main limitations of the approach, however, relate to determining the appropriate measurable indicators and the lack of reliable data on small states (Ram et al., 2019). Ram et al. (2019) argue that it also lacks appropriate considerations for the effects of climate change in the disaster reduction index.

\section{Other Economic, Social, and Environmental Indices}

This section summarises other vulnerability indices not covered in Section 3, most of which are also developed by international organisations. Some, like the HAI are used by the UN to determine LDC status, as previously discussed. The others have been considered for usage by various multilateral development banks and other concessionary finance bodies to assess vulnerability. These attempts will be discussed in Section 5 .

\section{UNDP Multidimensional Vulnerability Index (MVI)}

The MVI was proposed by Assa and Meddeb (2021) to update the UN EVI at the wake of the COVID-19 pandemic using three indicators: tourism revenue, remittances, and Foreign direct investment (FDI) inflows. Travel restrictions and the drying up of both remittance and investment flows during the pandemic has demonstrated how dependent SIDS are on such international flows of people and capital. The authors claim that the MVI, while not official, provides a richer lens on vulnerability. It finds more SIDS at the top vulnerability ranks than the EVI does. The authors propose that this measure be used for evaluating countries' eligibility for concessional financing, especially at the wake of COVID-19 since it makes clear that many SIDS are far more vulnerable than their income levels imply.

\section{Foundation for Studies and Research on International Development's (FERDI) Physical Vulnerability to Climate Change Index (PVCCI)}

According to Feindouno \& Guillaumont (2019), the PVCCI is built on principles similar to those of the UN EVI. A first version of this index was presented 2011 and has since been periodically refined. The uniqueness of the PVCCI is that it is designed for the allocation of adaption resources. A vulnerability index built for resource allocation must be independent of the country's policies; a performance-based approach may be considered unfair since other financial resources do not reflect the adaptation needs of the recipient countries.

Therefore, unlike other climate indicators, the $\mathrm{PVCCl}$ attempts to reflect the truly exogenous vulnerability that results from shocks which hit the country and for which it is not responsible. It relies on components which are measured from long-term trends in geo-physical variables 
related to climate change, without any use of socioeconomic data. These are presented in Figure 3 (Feindouno \& Guillaumont, 2019).

Figure 3: components and weighing of the PVCCI

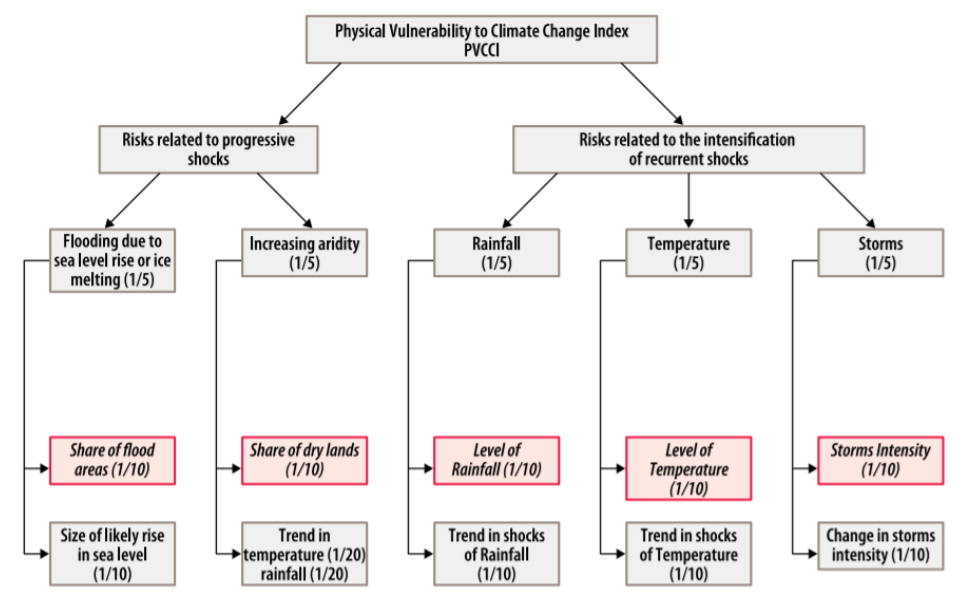

Source: Feindouno \& Guillaumont (2019, p. 5), reproduced with permission.

The PVCCl's average score for SIDS is very high as their intrinsic physical characteristics makes them particularly susceptible to natural disaster. However, high standard deviation values highlight the heterogeneity across the country group; the PVCCI is quite variable within the group of SIDS Non-LDCs, with vulnerability being greatest where local environments are already under stress as a result of human activities (Feindouno \& Guillaumont, 2019).

Since 2011, the PVCCI has been used in several circumstances. It has been used as part of a vulnerability assessment of Asian LDCs for the AsDB (Feindouno \& Guillaumont, 2019). It has also been used in a study requested by the AfDB that proposes new allocation criteria for concessional funds. These will be discussed in Section 5 .

\section{UN HAl and HDI indices}

The Human Asset Index (HAI) was developed by the United Nations Capital Development Fund (UNCDP) and it is one of the indicators used to classify LDCs along with GNI per capita and the UN EVI. It is a composite index containing education and health indicators (World Bank, 2018b). Generally, SIDS perform well on the HAl; as mentioned, most SIDS that are project to graduate from LDC will do so on ground of surpassing the HAl threshold, along with increases in GNI per capita (Ancharaz, 2019). However, HAI suffers from severe data constraints (World Bank, 2018b).

The Human Development Index (HDI) developed by the United Nations Development Program (UNDP) is used to rank countries by level of human development. It is a composite index of three dimensions: health (life expectancy at birth), education (mean years of schooling, expected years of schooling), and living standard (GNI per capita in PPP terms). Given the latter component, the $\mathrm{HDI}$ is positively correlated with per-capita income and hence does not provide an alternative measure of structural vulnerability for SIDS. The HDI has been criticised for its exclusive focus on national performance and ranking, lack of rationale for weighing the components equally, and measurement error of the underlying statistics (World Bank, 2018b). 


\section{The CRI and the CCVI}

The Germanwatch Global Climate Change Risk Index (CRI) ranks 182 developed and developing countries most affected by weather events based on indicators that capture loss of human life and loss of economic output. Because it summarises the extreme events during a period of 20 years, the index can be considered a good measure of exposure to natural hazards. However, the CRI suffers from limited data sources (World Bank, 2018b).

The Verisk Maplecroft Climate Change Vulnerability Index (CCVI) enables organisations to identify areas of risk within their operations, supply chains and investments. It evaluates 42 social, economic and environmental factors to assess national vulnerabilities across three core areas. These include exposure to climate-related natural disasters and sea-level rise; human sensitivity, in terms of population patterns, development, natural resources, agricultural dependency and conflicts; and future vulnerability by considering the adaptive capacity of a country's government and infrastructure to combat climate change. The countries with the most risk are characterised by high levels of poverty, dense populations, exposure to climate related events, and reliance on flood and drought-prone agricultural land (World Bank, 2018b).

\section{UN World Risk Index (WRI)}

The WRI calculates the risk of 171 countries based on four components: exposure to natural hazards (earthquakes, flooding, drought, sea-level rise); vulnerability as dependent on infrastructure, nutrition, living conditions, coping capacities as per governance, disaster preparedness, health care; adapting capacities. The index was calculated by the UN Institute for Environmental and Social Security. The WRI classifies countries in five categories of risk: Very High, High, Medium, Low, and Very Low. Scores are not available for 15 small state members (World Bank, 2018b). This is illustrated in the Table 3.

Table 3: WRI country classification

\begin{tabular}{|l|l|l|l|l|l|}
\hline \multicolumn{9}{|c|}{ WorldRiskIndex for SSF Countries, mean 2012-2016 } \\
\hline Very High & High & Medium & Low & Very Low & N/A \\
\hline Vanuatu & Djibouti & Lesotho & Namibia & Cyprus & Antigua \& B \\
Tonga & Suriname & Belize & Bahamas & Seychelles & Dominica \\
Solomon Isl & Bhutan & Gabon & Botswana & Estonia & Fed. Micronesia \\
Timor Leste & Swaziland & & Eq. Guinea & Kiribati & Maldives \\
Brunei Daruss & Comoros & & & Iceland & Marshall Islands \\
Mauritius & Trinidad \& Tob & & & Grenada & Montenegro \\
Fiji & & & Barbados & Nauru \\
Guinea Bissau & & & Malta & Palau \\
Jamaica & & & Qatar & St Lucia \\
Gambia & & & & Samoa \\
Guyana & & & & San Marino \\
Cape Verde & & & & & Sao Tome and P \\
& & & & & St Kitts \& N \\
& & & & & St Vincent \\
& & & & & \\
\hline
\end{tabular}

Source: World Bank (2018B, p. 33), licensed under Creative Commons Attribution 3.0 IGO (CC BY 3.0 IGO) 


\section{Attempts to Reconsider Allocation Approaches}

\section{The World Bank}

In IDA16, the World Bank considered an approach that would link IDA's allocations to a country's structural vulnerability. Specifically, the proposal involved replacing the current country performance rating (CPR) by a weighted average of CPR, the UN EVI the Human Assets Index (HAl). Supporters of this approach viewed the introduction of these indices as a method for providing a simplified and uniform allocation formula that could accommodate the heterogeneity of IDA-countries and eliminate the need for the SIEE (World Bank, 2018b).

Several problems emerged with the inclusion of EVI to the allocation formula. For one, vulnerability data are available every 3 or 4 years and is not available for all IDA eligible countries. The data also has significant time lags ( 3 to 5 years) which makes the allocation process backward looking. Additionally, it exhibits both volatility and stagnation depending on the specification used; this is problematic for the former as significant fluctuations in allocation undermines predictability. As for the latter, it would mean rigidity in the allocation system and difficulty in revising provision criteria (World Bank, 2018b).

Including EVI also results in some structural problems. For example, it will mean that the formula is double counting some variables, such as size of the population. Indeed, the World Bank (2018) argues the some of the structural vulnerabilities may already be captured in the current allocation framework through the impact of such factors on the GNI per-capita. Including the index will also have severe redistribution implication, with some countries receiving multiples of their current allocations, while others will experience significant allocation reduction (World Bank, 2018b).

\section{Africa Development Bank (AfDB)}

Similarly, the AfDB explored option to include vulnerability as one of its allocation criteria (Africa Development Bank, 2019b). The AfDB has already taken steps to include countries that are considered vulnerable or fragile. It has two main funding streams, the first is the Performance Based Allocation (PBA) and the second is the Transition Support Facility (TSF) for countries in fragile situation. The former is based on GNI per capita, population, and infrastructure, and the latter is based on peace and security indicators as well as commitment to pursue stability and transparency (Africa Development Bank, 2019b; Guillaumont \& Guillaumont-Jeanneney, 2009).

As part of the Fourteenth General Replenishment of the African Development Fund, the AfDB provided proposals to better address fragility drivers under the PBA system. It commissioned FERDI to carry out the independent study and explored methodological options to account for indicators capturing structural and climatic vulnerabilities of ADF-eligible countries. FERDI suggested using a combination of the several indices including the UN EVI and PCCVI, modified to fit the AfDB context (Africa Development Bank, 2019b).

- Option 1: Maintain the PBA system and reform the TSF allocations.

- Option 2: Maintain the PBA system and use a specific formula for TSF, but open access to all ADF-eligible countries, thus removing eligibility criteria for the TSF.

- Option 3: Merge TSF resources and the PBA envelope into a general ADF allocation system

- Option 4: Maintain TSF and introduce a vulnerability component into the PBA formula. 
The results of the analysis indicated that Option 4 represents a viable trade-off between performance, needs, and vulnerability. It would allocate more resources to transition states while remaining sensitive to countries' performance. AfDB was also keen to consider Option 1 since it could make it possible to align the TSF to more nuanced indicators of the key drivers of fragility in transition states, while preserving the PBAs (Africa Development Bank, 2019b).

The inclusion of the vulnerability index had its drawback, including posing an operational risk and resulting in high transaction costs due to the required data collection of a large number of indicators from different information sources. It will require a yearly collection of 30 metrics from 19 external data sources, for which frequency and information gaps exist (Africa Development Bank, 2019a; Asia Development Bank, 2019b).

As a result, the AfDB maintained that it will revise its framework in the next General Replenishment of the African Development Fund to reflect the findings of this consultation but will not include a vulnerability index as it is very costly and risky. It proposes maintaining the basic structure of the PBA formula with some minor modifications on discount rates and exponents of certain variables to allocate more resources to the TSF for countries with higher fragility and vulnerability (Africa Development Bank, 2019a, 2019b).

\section{Asia Development Bank (AsDB)}

Generally, access to the Asia Development Bank AsDB lending (the Asian Development Fund AsDF) options is largely determined by nominal per capita GNI, creditworthiness, and debt distress risks under the current resource allocation framework (Asia Development Bank, 2019a). This is recognised as unsuitable for SIDS because of their special characteristics, discussed breifly in Section 1. As a result, in AsDB (2019a), the bank put forth a framework to address the financial needs for SIDS, recognising that nominal GNI per capita is not an adequate measure of development needs among these countries as they are disproportionally vulnerable to shocks and face higher costs of living (Asia Development Bank, 2019a).

The report proposes that under AsDF 13 (period 2021-2024) the plan is to adopt a different approach for SIDS strategic planning and access to concessional finances. It will take into account the roots of vulnerability, and potential pathways to build resilience and stability - based on comprehensive fragility assessments and other relevant considerations (including institutional and capacity) (Asia Development Bank, 2019a). AsDB proposes an Economic Vulnerability Premium for AsDF eligible SIDS under AsDF 13. Its size will depend on the degree of vulnerability of a country, in contrast to the base allocation under AsDF 12, which allocated a uniform amount to all eligible countries. The Economic Vulnerability Premium aims to ensure additional financial resources for AsDF grant-eligible SIDS on top of their PBAs to help mitigate structural vulnerability. The allocation of the premium is proposed to be limited to the grant eligible SIDS because other AsDF grant-eligible countries benefit from much larger performancebased allocations (PBA) (Asia Development Bank, 2019a).

To do so, the UN EVI described in Section 2 emerged as the most appropriate option. While other indices were considered (including fragility indices, CRI, and WRI), they were not deemed suitable either due to their limited coverage or because they are too complex (Asia Development Bank, 2019b). Therefore, the UN EVI was chosen because of its relevance, data availability, simplicity, and comprehensiveness. Additionally, it is available for all AsDF grant eligible countries and it reflects key determinants of structural vulnerability of SIDS. Given the changes to 
the structure of the UN EVI every three years, the AsDB (2019) proposes making use of the Retrospective UN EVI (Asia Development Bank, 2019a). This measure updates the UN EVIs retroactively for previous years using the new structure. This calculation will allow the UN EVI values to be compared not just across countries but also intertemporally, i.e. for the same country over time (Feindouno \& Goujon, 2015).

SIDS are divided into groups based on their EVI scores, ranging from 0 to 100 , with a higher score indicating higher vulnerability (Asia Development Bank, 2019b). The proposed amounts of the Economic Vulnerability Premium will be based on their classification; the highest group comprises scores 70-80, and countries are allocated an amount of USD55 million per cycle, while the lowest group comprises scores 40-50 with an allocation of USD40 million (Asia Development Bank, 2019b). The EVI score for eligible countries is illustrated in Table 4.

Table 4: EVI scores for countries eligible for AsDF grants

\begin{tabular}{|l|l|c|}
\hline EVI Score & \multicolumn{1}{|c|}{ Country (ADF Grant-Eligible SIDS) } & Premium (\$ million) \\
\hline $70-80$ & Kiribati & 55 \\
\hline $60-70$ & Marshall Islands & 50 \\
\hline $50-60$ & $\begin{array}{l}\text { Federated States of Micronesia, Maldives, } \\
\text { Nauru, Solomon Islands, Tonga and Tuvalu }\end{array}$ & 45 \\
\hline $40-50$ & Samoa $^{\text {and Vanuatu }}$ & 40 \\
\hline
\end{tabular}

Source: Asia Development Bank (2019b, p.5), licensed under a Creative Commons Attribution (CC BY 3.0 IGO)

The AsDB recognises that integrating vulnerability indices in the performance-based allocation formula cannot fully address its shortcomings (Asia Development Bank, 2019b). While including the vulnerability indices in the allocation formula results in SIDS receiving higher allocations than before, the allocations for SIDS with small population remain very small. The variation in the resource allocations between the different SIDS is very wide, generating inadequate differences in country allocations. Additionally, as mentioned, the experiences from IDA and the AfDB in exploring the integration of fragility and vulnerability indices in the PBA system suggest considerable challenges, deriving from limited data availability, complexity of the model, and high transaction costs in developing the indices (Asia Development Bank, 2019b).

Finally, the AsDB recognises that UN EVI scores show little volatility since some parameters are generally time invariant. This means that resources allocation to eligible SIDS is likely to be relatively stable. It also recognises that the limited scope for increasing public revenues means that AsDB's SIDS may require more concessional resources for longer periods of time than other countries with similar income levels (Asia Development Bank, 2019a). This means that the transition to self-sufficiency and graduation is very challenging. Nevertheless, broader access to resources is still essential for SIDS as it can contribute to greater resilience to climate change, stronger regional integration, better institutions, substantial poverty reduction, and improved human development outcomes (Asia Development Bank, 2019a).

\section{Alternatives, Criticisms, and Other Considerations}

Some in the literature advocate for radically and fundamentally rethinking whether any incomecentric model is appropriate for SIDS, not only in light of their economic challenges, but also in the context of economic and biodiversity issues. The Dasgupta Review on the Economics of Biodiversity demonstrates that in order to judge whether the path of economic development is 
sustainable, nations need to stop relying on GDP as it is simply a measure of flow and adopt instead a system of economic accounts that records an inclusive measure of their wealth, including nature as an asset (Dasgupta et al., 2021; SIDS Access to Finance Roundtable, 2021).

Similarly, Campling (2006) believes that for the genuine 'sustainable development' of SIDS, there needs to be an emphasis on island people as active, key agents beyond just affirming the need to improve health and education outcome by international organisations. The Campling study (2006) advocates that sustainability can only be achieved through a democratic base of island citizens that cooperate and coordinate across the different islands. It suggests the conceptualisation of vulnerability and needs reflect broader power relations in the global political economy; this is evident by how the conceptualisations of SIDS have moved from an emphasis on socio-economic development in the 1970s, to geopolitical security in the 1980 s, to economic and environmental vulnerability in the 1990s.

Some of the experts that have been contacted for this rapid review doubted that external support could ever be sustainably reduced in SIDS. Some believe that SIDS will almost certainly require external support indefinitely, and that is without factoring in climate change. Once that is considered as a dimension, including potential impact on the tourism industry, the picture becomes bleaker. This, they claim, is now well recognised by many international organisations, including the World Bank. Self-sufficiency for SIDS becomes more distant with each external shock. The only alternative to external support is non-sovereignty or some form of labour mobility scheme, such as the ones that Australia and New Zealand have for some Pacific countries.

Other experts believe that there is a need to distinguish between SIDS to be able to answer whether or not they can sustain without external support. Islands like Kiribati, Tuvalu, Nauru, Tokelau, as well as Wallis and Futuna in the Pacific, they claim, will never be sustainable in any meaningful sense, neither environmentally nor financially. Therefore, donor countries need to recognise that some 'micro' states will never be self-sufficient. Compacts of Association are one option - like the Cook Island have with New Zealand, but this requires some pooling of 'sovereignty' which is unpopular. SIDS like Tonga, Samoa, Vanuatu, and the Solomon Islands will survive without external aid, but living standards will likely fall to subsistence levels. Larger SIDS- such as Fiji and Papua New Guinea - have more chances to be 'sustainable' precisely because they have larger populations and more resources.

\section{Conclusion}

This aim of this paper was to shed light on whether vulnerability indices can help determine the levels of external support for SIDS. This was achieved by considering the different indices that international organisations and multilateral development banks use (or considered using) to capture the vulnerability of SIDS and how they define thresholds for aid allocation. Some of the benefits and drawbacks of these indices were also discussed, especially in terms of their ability to capture dimensions of vulnerability and their applicability given limited data.

Generally, the advantage of using vulnerability indices over income measures is that they are able to capture the intrinsic characteristics of SIDS that leave them exposed to external shocks, even if they perform well in measures like GNI per capita. Additionally, because they can determine the shape and scope of vulnerability, these indices may be used to inform how aid can be allocated within SIDS to build resilience. 
However, the difficulty of discussing when vulnerability is at a threshold that makes the reduction in external support for SIDS sustainable stems from the fact that vulnerability as it is defined by most organisations is meant to capture inherent characteristics of SIDS, which cannot be changed through external support. This means there is no clear pathway to the reduction in aid, no matter their income or development levels. Additionally, one of the biggest practical challenges in capturing vulnerability is the dearth of data on SIDS due to their dispersed geographies, making it difficult and expensive to collect.

The COVID-19 pandemic is expected to disproportionately impact SIDS due to the global collapse of tourism, a key sector for many of these small island nations. This situation exemplifies the vulnerability of SIDS to external shocks and the need to account for it when allocating external support. Between the different indices discussed in this paper, the Commonwealth EVI/ERI framework is arguably the best positioned to provide warning signs for similar external shocks in the future. This is because the framework is able to capture both inherent characteristics and policies in place, meaning it can pinpoint to specific areas where shocks will be particularly harmful as there is inadequate contingencies or infrastructure to counteract them. 


\section{References}

Africa Development Bank. (2019a). A Technical Note on Introducing a Vulnerability Component in the ADF Allocation Framework. Africa Development Bank. https://adf.afdb.org/system/files/2020-09/RAF\%20\%26\%20Vulnerability\%20\%20Technical\%20Note.pdf

Africa Development Bank. (2019b). Introducing a Vulnerability Component in the ADF Allocation Framework [Technical note]. Africa Development Bank. https://adf.afdb.org/system/files/2020-09/Fragility\%20\%20Introducing\%20a\%20Vulnerability\%20Component.pdf

Alonso, J., Cortez, A., \& Klasen, S. (2014). LDC and other country groupings: How useful are current approaches to classify countries in a more heterogeneous developing world? CDP Department of Economic \& Social Affairs. https://www.un.org/en/development/desa/policy/cdp/cdp_background_papers/bp2014_21 .pdf

Ancharaz, V. (2019). Graduating from LDC Status: A Focus on Small Island Developing States (SIDS) (International Trade Working Paper No. 2019/04; International Trade Working Paper, Vol. 2019/04). https://doi.org/10.14217/b2df5803-en

Asia Development Bank. (2019a). A Framework for Addressing the Financing Needs of Small Island Developing States [ADF 13 Replenishment Meeting].

https://www.adb.org/sites/default/files/page/561776/framework-financing-needs-sidsdiscussion-paper.pdf

Asia Development Bank. (2019b). Update on ADF 13 Resource Allocation Framework. Asia Development Bank. https://www.adb.org/sites/default/files/institutionaldocument/614446/adf13-2020-resource-allocation-framework-update.pdf

Assa, J., \& Meddeb, R. (2021). Towards a Multidimensional Vulnerability Index [Discussion Paper]. UNDP. https://www.undp.org/content/dam/undp/library/km-qap/UNDP-Towardsa-Multidimensional-Vulnerability-Index.pdf

Baldacchino, G. (2015). Building the Resilience of Small States: A Revised Framework. The Round Table, 104(4), 517-519. https://doi.org/10.1080/00358533.2015.1064592

Briguglio, L. (1992). Preliminary Study on the Construction of an Index for Ranking Countries according to their Economic Vulnerability,. UNCTAD.

Briguglio, L. (1995). Small island developing states and their economic vulnerabilities. World Development, 23(9), 1615-1632. https://doi.org/10.1016/0305-750X(95)00065-K

Briguglio, L. (2018). The Vulnerability of Small States. In Small States: Economic Review and Basic Statistics, Volume 20. Commonwealth Secretariat.

Briguglio, L., Cordina, G., Farrugia, N., \& Vella, S. (2009). Economic Vulnerability and Resilience: Concepts and Measurements. Oxford Development Studies, 37(3), 229-247. https://doi.org/10.1080/13600810903089893 
Caribbean Development Bank. (2017). Special Development Fund Annual Report. Caribbean Development Bank. https://www.caribank.org/sites/default/files/publicationresources/SDF-9_35_AM_3-SDF-AnnualReport_2017_1.pdf

Crowards, T. (2000). An index of inherent economic vulnerability for developing countries. Barbados: Caribbean Development Bank.

Dasgupta, P., Großbritannien, \& Treasury. (2021). The economics of biodiversity: The Dasgupta review.

https://assets.publishing.service.gov.uk/government/uploads/system/uploads/attachment _data/file/957291/Dasgupta_Review___Full_Report.pdf

Feindouno, S., \& Goujon, M. (2015). The retrospective economic vulnerability index. FERDI. https://ferdi.fr/dl/df-AboGKbonGun6wvceDkpVKxFj/ferdi-p147-the-retrospectiveeconomic-vulnerability-index-2015-update.pdf

Feindouno, S., \& Guillaumont, P. (2019). Measuring physical vulnerability to climate change: The $\mathrm{PVCCl}$, an index to be used for international development policies. 12.

Guillaumont, P. (2010). Assessing the Economic Vulnerability of Small Island Developing States and the Least Developed Countries. Journal of Development Studies, 46(5), 828-854. https://doi.org/10.1080/00220381003623814

Guillaumont, P., \& Guillaumont-Jeanneney, S. (2009). Accounting for Vulnerability of African Countries in Performance Based Aid Allocation. Africa Development Bank Group. https://www.afdb.org/fileadmin/uploads/afdb/Documents/Publications/WORKING\%20103 _\%2022\%20\%20January\%202009.pdf

Herbert, S. (2019). Development characteristics of Small Island Developing States. K4D Helpdesk Report.

https://opendocs.ids.ac.uk/opendocs/bitstream/handle/20.500.12413/14624/623_Develop ment_Characteristics_of_Small_Island_Developing_States_Final.pdf?sequence=1

OECD. (2018a). Transition Finance in Least Developed Countries and Small Island Developing States: Cabo Verde Country Pilot.

http://www.oecd.org/officialdocuments/publicdisplaydocumentpdf/?cote=DCD/DAC(2019) 4\&docLanguage $=$ En

OECD. (2018b). Making Development Co-operation Work for Small Island Developing States. OECD. https://doi.org/10.1787/9789264287648-en

OECD. (2021). COVID-19 pandemic Towards a blue recovery in small island developing states [Tackling Coronavirus]. https://read.oecd-ilibrary.org/view/?ref=1060_1060174tnkmsj15ap\&title=COVID-19-pandemic-Towards-a-blue-recovery-in-small-islanddeveloping-states

Quak, E. (2019). How losing access to concessional finance affects Small Island Developing States (SIDS). https://opendocs.ids.ac.uk/opendocs/bitstream/handle/20.500.12413/14595/626_SIDS_g raduation_impacts_losing_concessional_finance.pdf?sequence $=1$ 
Ram, J., Cotton, J., Fredrick, R., \& Elliot, W. (2019). Measuring Vulnerability: A Multidimensional Vulnerability Index for the Caribbean. 51.

SIDS Access to Finance Roundtable. (2021). Measures of Development Discussion Note.

UN. (2010). LDC Identification Criteria \& Indicators / Department of Economic and Social Affairs. https://www.un.org/development/desa/dpad/least-developed-country-category/ldccriteria.html/

UN. (2015). Small Island Developing States in Numbers Climate Change Edition. Office of the High Representative for the Least Developed Countries, Landlocked Developing Countries and Small Island Developing States. https://sustainabledevelopment.un.org/content/documents/2189SIDS-IN-NUMBERSCLIMATE-CHANGE-EDITION_2015.pdf

UN. (2018). Monitoring of Graduated and Graduating Countries from the Least Developed Country Category: Samoa [Committee for Development Policy 20th Plenary Session]. United Nations. https://www.un.org/development/desa/dpad/wpcontent/uploads/sites/45/CDP-PL-2018-3d.pdf

UN. (2020). Assessment of financing for development flows SIDS.

https://www.un.org/ohrlls/sites/www.un.org.ohrlls/files/assessment_of_financing_for_dev elopment_flows_sids_24.06.2020.pdf

UN. (2021a). LDC Identification Criteria \& Indicator.

https://www.un.org/development/desa/dpad/least-developed-country-category/ldccriteria.html/

UN. (2021b). Monitoring of Countries Graduated from the Least Developed Country Category: Samoa [Committee for Development Policy 23 rd Plenary Session]. United Nations. https://www.un.org/development/desa/dpad/wp-content/uploads/sites/45/CDP-PL-2021 PL-5A.2.pdf

Wang, C. (2013). Reconsidering the economic vulnerability index of the United Nations. Canadian Journal of Development Studies, 34(4). https://www.tandfonline.com/doi/abs/10.1080/02255189.2013.814566

World Bank. (2018a). DA18 Mid-Term Review Transitioning out of IDA financing: A review of graduation policy and transition process. World Bank. http://documents1.worldbank.org/curated/en/648731542748974532/pdf/ida18-mtrgraduation-policy-review-10312018-636767929247403732.pdf

World Bank. (2018b). Small States: Vulnerability and Concessional Finance [Technical Report]. World Bank. http://pubdocs.worldbank.org/en/339601536162647490/Small-StatesVulnerability-and-Concessional-Finance.pdf

World Bank. (2020). The World Bank In Small States. World Bank. https://www.worldbank.org/en/country/smallstates/overview 


\section{Acknowledgements}

We thank the following experts who voluntarily provided suggestions for relevant literature or other advice to the author to support the preparation of this report. The content of the report does not necessarily reflect the opinions of any of the experts consulted.

- Dr Emily Wilkinson - Overseas Development Institute

- Mr Graham Teskey - Abt Associates

- Mr James Gilling - DFAT Australia

- Mr Scott Hook - consultant with expertise on Pacific resilience

- Dr Stuart Davies - United Nations Barbados \& the Eastern Caribbean

\section{Suggested citation}

Knowledge for Development Programme (2021). Using Indices to Capture Vulnerability for Development Finance in SIDS. K4D Helpdesk Report 982. Brighton, UK: Institute of Development Studies. DOI: 10.19088/K4D.2021.066

\section{About this report}

This report is based on 14 days of desk-based research. The K4D research helpdesk provides rapid syntheses of a selection of recent relevant literature and international expert thinking in response to specific questions relating to international development. For any enquiries, contact helpdesk@k4d.info.

K4D services are provided by a consortium of leading organisations working in international development, led by the Institute of Development Studies (IDS), with Education Development Trust, Itad, University of Leeds Nuffield Centre for International Health and Development, Liverpool School of Tropical Medicine (LSTM), University of Birmingham International Development Department (IDD) and the University of Manchester Humanitarian and Conflict Response Institute (HCRI).

This report was prepared for the UK Government's Foreign, Commonwealth and Development Office (FCDO) and its partners in support of pro-poor programmes. Except where otherwise stated, it is licensed for non-commercial purposes under the terms of the Open Government Licence v3.0. K4D cannot be held responsible for errors, omissions or any consequences arising from the use of information contained in this report. Any views and opinions expressed do not necessarily reflect those of FCDO, K4D or any other contributing organisation.

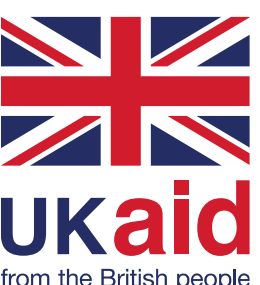

(C) Crown copyright 2021. 